\title{
RELACIONAMENTO NÃO DIRETIVO DO ENFERMEIRO COM PACIENTE EM PROCESSO DE RESSOCIALIZAÇÃO**
}

\author{
Sonia Regina Zerbetto ** \\ Antonia Regina Furegato Rodrigues ***
}

ZERBETO, S.R..;RODRIGUES, A.R.F., Relacionamento não diretivo do enfermeiro com paciente em processo de ressocialização. Rev.latino-am.enfermagem, Ribeirão Preto, v. 5, número especial, p. 77-83, maio 1997.

Este trabalho teve como objetivo experienciar e analisar uma interação enfermeira-paciente com uma abordagem nãodiretiva, centrando a atenção no paciente em fase de ressocialização. Teve como fio condutor princípios extraídos dos trabalhos de Rogers e de sua aplicação na enfermagem por Braga e Rodrigues. O novo projeto de ressocialização de pacientes de um macro-hospital estatal é acompanhado, supervisionado e conta com uma moradia na cidade onde pacientes experimentam conduzir suas vidas como cidadãos comuns. Uma paciente, em fase de adaptação deste programa, concordou em participar da entrevista com o enfermeiro. O relacionamento não-diretivo foi registrado e analisado, ressaltando-se os sentimentos do enfermeiro, assim como suas intervenções considerando as comunicações verbais e não verbais. A ansiedade do enfermeiro foi identificada principalmente no que se refere à aplicação da técnica e a ansiedade da paciente refletia as consequências de sua adaptação fora do ambiente hospitalar.

UNITERMOS: ressocialização, enfermagem psiquiátrica, relação interpessoal

\section{INTRODUÇÃO}

A interação entre o profissional e a pessoa que busca ajuda ocorre num processo comunicativo através do qual as duas pessoas agem e reagem. Tanto um como o outro comportam-se de acordo com seu modo próprio de reagir diante de cada situação, com sentimentos, emoções, ansiedades e preconceitos.

O enfermeiro, entretanto, é o profissional e espera-se que ele tenha conhecimentos técnico e de sua própria pessoa suficientes para poder ajudar o outro no momento da interação.

Para RUDIO (1991, p.11), na "relação de ajuda que se estabelece com o indivíduo, a orientação nãodiretiva enseja que a atenção não se focalize sobre o problema da pessoa, mas sobre a própria pessoa, ou melhor, sobre o seu crescimento, desenvolvimento, maturidade, seu melhor funcionamento e maior capacidade para enfrentar a vida”.

A orientação não-diretiva estimula a comunicação da pessoa consigo mesma e o indivíduo tem em si o seu centro de avaliação (RODRIGUES, 1993). As ações do terapeuta são dirigidas para identificar as necessidades da pessoa que apresenta problemas, para ajudá-la a tomar consciência e examinar todos os fatos envolvidos na situação e para encontrar as suas próprias soluções.

Ainda dentro deste enfoque, MUCHIELLI (1978) destaca alguns pontos que o terapeuta precisa considerar durante o processo interativo: estar atento ao outro e não julgá-lo; ter a intenção autêntica de compreender o outro em sua própria maneira de ser, de pensar em seus termos, permitindo descobrir seu universo subjetivo, possibilitando apreender as significações que a situação tem para o cliente. Além disso, esforçar-se continuamente para manter-se objetivo e para ter consciência do que se passa no decorrer da relação de ajuda.

"O relacionamento que o terapeuta não-diretivo estabelece não é frio, distante e profissional. É um contato de pessoa para pessoa, num clima afetivo de responsabilidade e profissional. O terapeuta tem para com o cliente consideração positiva incondicional e o indivíduo sente-se respeitado tal como é. Através da compreensão empática, o cliente sente que ele é para si, um "outro eu" tendo as 'mesmas' percepções e os 'mesmos' sentimentos, fontes de compreensão verdadeira. Assim, o cliente pode ser congruente, sendo realmente o que é, sem necessidade de esconder-se atrás de 'máscaras'ou 'fachadas'” (RUDIO, 1991, p.14).

\footnotetext{
* Projeto elaborado na disciplina ERP-731 "Relacionamento Interpessoal Enfermeiro-Paciente"

** Pós-graduanda do Mestrado em Enfermagem Psiquiátrica -EERP - USP

*** Doutora em Enfermagem. Professora do Departamento de Enfermagem Psiquiátrica e Ciências Humanas da EERP - USP
} 
Neste contexto o enfermeiro, no papel terapêutico não-diretivo, tem a função de um facilitador isto é, alguém que ajuda o outro a escontrar soluções para os seus problemas, sem pré deteminá-las (RODRIGUES,1993).

A experiencia de uma interação enfermeiropaciente com abordagem não-diretiva, centrando a atenção no paciente, procurando ser terapêutico, teve como fio condutor os seguintes princípios extraídos dos trabalhos de ROGERS e utilizados por BRAGA \& RODRIGUES (1992):

1) O contato de duas pessoas;

2) Vulnerabilidade e ansiedade do cliente;

3) Congruência do terapeuta em sua relação com o cliente;

4) Compreensão empática do quadro de referência interna do outro;

5) Atenção positiva incondicional;

6) Percepção pelo cliente da atenção positiva incondicional e da compreensão empática do terapeuta, a seu respeito.

\section{OBJETIVO}

Estabelecer e analisar o relacionamento terapêutico com o paciente em processo de ressocialização, segundo a visão humanista de assistência.

Avaliar a abordagem não-diretiva utilizada na interação, a partir do embasamento teórico sobre relacionamento terapêutico, centrado na pessoa em relação de ajuda.

\section{PROCEDIMENTO}

Em função da vivência, enquanto enfermeira psiquiátrica de um macro hospital estatal psiquiátrico de Ribeirão Preto, foi possível interagir com pacientes "moradores" daquela Instituição e que participavam do processo de ressocialização, para poderem vivenciar uma experiência fora do hospital, como cidadãs comuns.

Este novo projeto consiste na vivência de exmoradoras do referido hospital em uma residência na cidade de Ribeirão Preto, onde elas têm a oportunidade de tentar viver como cidadãs comuns, sob a supervisão direta de pessoas da comunidade e indireta pelo hospital. Esta moradia é chamada de Pensão Protegida.

Para que se fizesse a entrevista com uma paciente que estava em processo de adaptação nessa pensão protegida, foi feito contato prévio com a enfermeira que supervisionava este projeto e com a paciente, sendo ambas informadas dos objetivos e solicitados suas permissões.

A paciente foi orientada quanto ao motivo da entrevista e sobre o uso de um gravador. Além desses contatos prévios, foi encaminhado à Instituição um ofício, especificando o objetivo da entrevista.

Por que foi escolhida esta paciente? Por ela ser conhecida como interna no hospital, por haver um relação empática com a enfermeira e, também, por ela estar vivenciando a experiência que gostaríamos de avaliar.

Após estes esclarecimentos e aceitação da paciente, foram marcados o dia e a hora para o encontro.

A entrevista gravada durou quarenta minutos. A transcrição desta foi apresentada em sala de aula para discussão na disciplina ERP-731 Relacionamento Interpessoal Enfermeiro-Paciente.

Através da análise da interação, feita pelo grupo, foi possível destacar os pontos importantes da comunicação embasados na abordagem humanista, aqui apresentados como P1, P2, P3... (falas do paciente) e $\mathrm{E} 1, \mathrm{E} 2, \mathrm{E} 3, \ldots$ (falas do enfermeiro).

Foi também possível dar destaque a alguns sentimentos do pesquisador que interagiu com a paciente.

\section{APRESENTAÇÃO E ANÁLISE DA INTERAÇÃO ENFERMEIRO-PACIENTE}

\section{a) A paciente e o contexto:}

T.S.P., 53 anos, solteira, com diagnóstico de epilepsia, foi internada em H.P.R.P., há vinte e cinco anos, através do encaminhamento de uma carta de um político, solicitada pela família, autorizando tal internação. Faz uso de medicação anticonvulsivante.

Esteve internada em outros hospitais psiquiátricos, tais como Juqueri (em Franco da Rocha) e Barra Funda (São Paulo) e, posteriormente transferida para Ribeirão Preto.

Foi paciente do pavilhão do CERMAM (Centro de Reabilitação Maria Aparecida Minzoni) e posteriormente na unidade Vila Terapêutica, ambos com objetivos de ressocialização. Atualmente, encontra-se na Pensão Protegida, projeto concretizado em final de 1992.

Citaremos, na íntegra, a interação, em forma de diálogo precedido das letras "P"e "E", significando respectivamente as iniciais de paciente e enfermeira.

Fomos para a residência acompanhada pela enfermeira supervisora. A paciente veio nos receber, cumprimentando-nos com abraços e beijos. Encaminhounos à sala e serviu café. Recebeu orientações da outra enfermeira sobre sua medicação e sobre um Ato Público que ocorreria dia 18/05/93, da luta antimanicomial, para o qual foi convidada a participar. Foi ainda informada sobre sua alta hospitalar. A paciente expressou alegria através de risos e gargalhadas e disse: "Nossa, meu Deus, até que enfim, livre. Vinte e cinco anos, vinte e cinco anos, 
quase "Bodas de Prata". Faria vinte e cinco anos em agosto que eu estava no hospital".

Observamos lágrimas em seus olhos. Houve um silêncio e, depois, ela colocou as mãos nos olhos e disse: "Não estou chorando de frescura, mas é muita coincidência, hoje é o dia da enfermeira e amanhã o dia de abolição dos escravos". Levantou-se, perguntou se éramos enfermeiras e nos cumprimentou pelo dia. Depois, levantou as mãos para cima, dirigida rumo ao céu e falou: "Quem diria que um dia eu ia chegar aqui".

Após receber as informações, solicitamos à paciente que escolhesse um lugar onde pudéssemos ficar com privacidade e ela escolheu seu quarto. Fechou a porta e sentou-se numa cama e eu sentei-me na outra, à sua frente que segundo ela, não tinha dono.

Expliquei novamente que não seria uma entrevista como ela estava acostumada a fazer (com jornalistas de rádio e televisão). Ela referiu que tinha entendido e obtive sua autorização para gravar e discutir a gravação com o grupo da disciplina. Reforcei que teríamos um tempo de aproximadamente quarenta minutos.

\section{b) Descrição da informação:}

P1 - Possso começar?(risos) Oh! Meu Deus do Céu (silêncio).

P2 - Bem, S., o que eu tenho a dizer a você é uma coisa muito simples. No S.T. (Hospital), eu não, não me senti como um "pássaro cativo", como uma presidiária, como as demais do que eu. Lá para mim, era um pequeno paraíso, mas eu estava sob a custódia do hospital do governo. Sobre..., mesmo seguir restrições médicas e hospitalar, enfim tudo. Mas aqui, eu me sinto como uma cidadã, que eu vou à padaria buscar pão, eu vou à floricultura... Aqui cuidando de uma casa pequena, como se fosse (pausa) nossa casa (enfática e lenta). Eu mesma já fiz comida. A M. (outra ex-paciente) precisou de ir ao médico, esses dias aí; eu fiz a comida, elas (ex-pacientes) gostaram e aqui eu estou novamente reatando a forma de viver numa pequena comunidade! Isso não é uma comunidade, é uma residência! Não é?

E1 - Hum.... (com sinal afirmativo de cabeça).

P3 - Então, aqui estou voltando novamente, como se estivesse saído do "ventre materno", que é o S.T.; cortei o cordão umbilical do S.T.. Estou agora livre e pronta para vencer quaisquer vicissitudes.

E2 - Hum! Deixa ver se entendi: Então S.T. para você era como uma mãe e você se sente agora independente. P4 - É ...sinto-me livre (silêncio).

E3 - Sente-se livre pois lá parecia prisão?

P5 - Não, não como presa, mas....é, tinha que obedecer ordens, restrições lá do hospital, não é? As ordens de lá... mas nunca me senti uma presa lá; ia para todo lugar, mas tinha a restrição do portão, não é? Não podia sair sem acompanhamento de uma funcionária ou de outro funcionário, ou então por ordem da diretoria, com papel assinado para a gente ir, nem que, que seja lá no médico para fora do portão só.

E4 - Hum ...Hum...(compreensivo)

P6 - E então, já aqui não. A gente volta para onde quer. A gente se sente como um passarinho livre, né? Como um pássaro livre (risos). Um pássaro livre, em liberdade, né! Nunca eu achei uma coisa tão linda, tão maravilhosa do que a gente novamente conseguir a liberdade. E é tanta gente que quer acabar com a liberdade do ser humano, né? Isso é tão triste (abaixa a cabeça e levanta), porque todos nós devemos, nós merecemos, isso é uma coisa que todos nós temos direito.... é a liberdade. A liberdade é uma coisa muito importante, mas nós também precisamos saber gozar da liberdade, não é?

E5 - Eu estou entendendo que a liberdade é importante para você, mas você acha também que precisa saber como gozar da liberdade.

P7 - É. Qualquer restrição à todas às ordens que o cidadão tem que seguir, não é mesmo? Como por exemplo: tem leis, como as leis de trânsito, tem leis do cidadão, quando chega um policial perguntando à gente se temos carteira de identidade. Nós temos que pensar, não é mesmo? Mas isso aí são outros quinhentos do que o do hospital, não é? E6 - Hum.... (compreesivo) (Tentei falar, mas P. continuou)

P8 - No hospital é tudo lá nos papéis, né, pelos papéis. Era tudo ... assim que nem teleguiado e aqui ... não, a gente faz a gente mesmo, não é? Hoje fomos à feira, trouxemos de lá pão. Eu mesma paguei com o meu dinheiro. Só mesmo a gente voltando ao câmbio que eu já havia me esquecido lá, do meu custo de vida. Como é que são os custos, quando fomos lá na feira, tem que ver... e eu fui observando, como a gente faz ... pagar ... como viver (bate palmas) como um cidadão, como uma cidadã (tosse). E a gente, como por exemplo: veja a cidadania como é muito importante, mas a cidadania não se compra por dinheiro nenhum. É como a liberdade né! A saúde, a cidadania e liberdade, não é mesmo? São tres coisas fundamentais para a vida da gente, para a gente poder viver sossegada, né, em paz, consigo mesmo e com a comunidade.

E7 - Deixa eu ver se entendi: Você está sentindo como é viver em paz ... (P. interrompe)

P9 - (risos) Perfeitamente. Já fiz amizade com os vizinhos aqui. As garotas (vizinhas) vieram conversar comigo, viram que tudo que eu respondi era coerente e então, modéstia a parte, também prolixa, não é? Porque eu aprendi tudo o que eu dizia, era como elas (garotas) estavam aprendendo na escola. A professora ainda não me ensinou, como ditongos, tritongos, hiatos, muito da história do Brasil, como muitas coisas que elas não sabiam e elas gostaram muito e viram que eu era uma criatura 
que era coerente, né? Imagine, de um hospital psiquiátrico uma paciente desta, né, e tudo que ela (paciente) diz é coerente e então aí dá para perceber que nem tudo está perdido neste mundo, não é? Vinte e cinco anos num hospital não é brincadeira (falando pausadamente). Se eu não aprendi em vinte e cinco anos, então eu não aprendo nunca mais em minha vida né! Mas eu aprendi muita coisa. Bom, como eu digo, lá teve seus espinhos, mas teve muitas rosas. Eu pude colher muita coisa boa, aprender muita coisa, que eu sinto saudades de lá, de todas as pessoas e sei que todos estão sentindo a minha falta também e isso aí é uma coisa que quando eu vejo a B. (outra paciente do S.T.) eu pergunto, como é gente, estão sentindo a minha falta? Então o A. (motorista do hospital) diz: "Ah! O hospital está de luto". (Risos da paciente).

E8 - Hum... Estou entendendo que você apesar de ter vivido 25 anos no hospital, não foi fácil, mas aprendeu muita coisa boa e sente saudade das pessoas de lá e elas também estão sentindo saudade de você.

P10 - É. Ah! Eu fiquei muito lisonjeada, mas vir morar numa casa como esta, foi um caso inusitado, né! O Dr. A.K. viu que isto aí, deu certo, que é, foi uma beleza, né, as pensões protegidas que como estão tentando agora acabar com os manicômios, né! E novamente dar uma oportunidade aos seres humanos que, afinal de contas, nós somos seres humanos, temos o direito, a novamente voltar a ser cidadãos. Não é porque ficamos doentes que vão levar isso aí, como se fosse uma pessoa que esteja em um presídio, um presidiário,não é? Os presidiários têm direito a voltar novamente a conviver como cidadãos. Então imagine nós que não temos culpa nenhuma em ficar doentes. A doença vem por Deus, né!

E9 - Entendo que você está dizendo que o doente mental é um ser humano que tem direito de ser cidadão, assim como o presidiário e que o doente mental não é um presidiário.

P11 - É. Estou fazendo uma comparação. Se eles têm o direito de voltar a ser cidadãos, nós muito mais. Nós não cometemos nada, não roubamos, não fizemos nenhuma coisa que seja uma irregularidade. E no hospital a gente foi para tratar da saúde e a gente estava doente. Um médico me explicou que eu tinha complexo de Édipo. Posso contar sobre o complexo de Édipo?

E10 - Você quer contar?

P12 - Quando eu era criança, era uma criança muito arteira. E meu pai não, não, não perdoava quando a gente fazia travessuras. E então ele me batia muito. Mas a mamãe ficava com pena de mim e me cobria de carinhos e o meu pai não. E então eu sentia que o meu pai não gostava de mim, então eu fui criando uma criança assim, sabe, a metade de mim muito cheia e a metade vazia. Então quando eu cheguei no S.T., eu vi o quanto faz falta o carinho paterno também; mas lá encontrei Dr. G., Dr.
M., Dr. F., qual outro médico meu Deus do Céu ... (ansiedade), Dr. A.M., e meu Deus do Céu... Eles preencheram todo aquele lado vazio, do complexo de Édipo. Mas a história universal, (tosse) o de Édipo foi muito pior,ele detestava o pai e amava a mãe, detestar o pai, assim também não, né. Mas eu tinha.... que amava o meu pai, compreende? Meu pai era um homem que ele era perfeccionista, quer dizer, não admitia erros. A gente tinha que andar ali na linha mesmo sabe, se não andasse, se fizesse uma coisa... acontecia aquelas coisas indecentes, que eram travessuras sem maldade nenhuma. Aí então eu fiquei com a metade de mim um tanto vazia, por falta de carinho paterno, mas lá, no S.T. eu encontrei médicos, pessoas que preencheram todo aquele lado vazio.

E11 - Estou entendendo que você sentiu que estava complementada a parte vazia, que era a parte paterna com as pessoas, que conheceu no S.T., como por exemplo os médicos? (Junto comigo P. complementava minhas falas afirmando).

P13 - Eu me senti uma pessoa inteira. Assim como dois pratos de uma balança, né! Quando um está muito cheio, o outro sobe. Precisa haver equilíbrio nos dois pratos da balança (fez movimento com as mãos), compreende? Isso aí, acabou com o complexo de Édipo.

E12 - Hum! Então se entendi você está se sentindo equilibrada.

P14 - Sim. Aquela metade que estava vazia, ela foi preenchida pelo amor paterno que eles me deram.

Nesse momento, a outra enfermeira bateu à porta. Agradeci sua colaboração desejando-lhe sucesso nessa nova experiência de sua vida.

\section{c) Análise da interação}

Nessa análise, daremos destaque tanto aos sentimentos do enfermeiro quanto às comunicações interpessoais, reforçando os comentários com citações pertinentes.

Logo na primeira fala (E1), senti que a paciente estava solicitando uma resposta direta, por isso afirmei "hum, hum", fazendo movimento afirmativo com a cabeça. Daí, ela prosseguiu.

Em E2 e E3, fiquei ansiosa. Devido à resposta anterior na qual usei o termo "independente"e a paciente respondeu como "livre", precedido de breve intervalo de silêncio, tentei esclarecer para mim tal dado. Fiquei na dúvida quanto à adequação de minha comunicação e se esta teria sido um julgamento ou uma interpretação. Introduzi a palavra "prisão" para contrapor à "liberdade"e ela imediatamente retrucou dando detalhes, mostrandome que mesmo não estando livre, não considerava o hospital como prisão.

É interessante ressaltar que o enfermeiro pode 
por vezes errar no seu julgamento, na sua interpretação ou ter ponto de vista divergente. Entretanto, o fato de estar atento (avaliando suas comunicações e as do outro), de permitir ao paciente explicitar seu ponto de vista, de considerar o que foi apresentado pelo outro e seguir com ele em sua comunicação, minimiza os problemas e evita uma atitude não terapêutica.

Nesse caso, foi o que aconteceu. Permitindo que P. verbalizasse, ela seguiu seu raciocínio, informando e na pausa, eu emiti "hum, hum"facilitando a continuação numa atitude compreensiva.

Em E5 comuniquei com minhas palavras a compreensão que tive. Além disso, percebi em P6 que a paciente deixou transparecer sinais de tristeza e uma certa ansiedade ao falar da liberdade merecida pois torcia os dedos das mãos enquanto falava. Ela concordou com minha colaboração em E5 e prosseguiu, porém em E6 quando tentei falar, ela não permitiu. Percebi que ela tinha necessidade de continuar falando sobre o hospital e completar as idéias.

Durante a fala (P8), a paciente batem palmas e tossem. Tive a percepção de certa emoção como se as palmas fossem para acertar o compasso da palavra "viver"e talvez até de sua vida.

Preocupada por eu não estar falando nada, tentei demonstrar que a acompanhava e a compreendia em sua comunicação, pedindo-lhe então permissão para falar (E7). Ao começar a expor minha idéia ela interrompeu (riu, concordou) e continuou até que, de repente, passou a falar pausadamente (P9). Percebi certa angústia ao falar que nem tudo estava perdido. Foi fazendo sua análise comparando os prós e contras da situação e seus sentimentos foram aflorando até falar do luto no hospital pela sua saída.

Este foi então o momento adequado para fazer um apanhado da situação apresentada destancando os sentimentos que talvez lhe causassem angústia ou mal estar. Como diz RODRIGUES (1993), a não diretividade é uma técnica muito utilizada por Rogers que prevê uma participação ativa do facilitador, sem interferir com as mensagens que a pessoa vem explicando e a demonstração de seu entendimento sobre o que está sendo comunicado.

Em P10, a paciente volta à superficialidade, porém, aos poucos emite seu parecer sobre doença e doente mental, até colocar-se pessoalmente na situação. Ao perceber isto, pediu-me permissão para falar de si. Deixei a decisão por sua própria conta e ela prosseguiu apresentando sua visão de como ficou doente e como resolveu seu conflito.

Quando a paciente fazia o relato em P12, percebi que estava ansiosa e o quanto estava atingida emocionalmente.

Em E11, tentei novamente ajudá-la a prosseguir em sua comunicação e enquanto eu falava, ela completava as falas comigo. Senti que havia uma congruência e um bom entrosamento de ambas as partes e compreensão empática nesta interação.

Infelizmente, a interação foi interrompida pela entrada da enfermeira que estava nos aguardando, mas pela sequência do diálogo e sua conclusão, estávamos num momento tranquilo e a interrupção não chegou a ser danosa.

$\mathrm{Na}$ transcrição desse diálogo, percebemos que foi usada várias vezes a expressão: "Entendi"; "Estou entendendo...", o que nem sempre era necessário pois a eu estava de fato, atenta, interessada e apresentando atitudes compreensivas. Apesar disso, percebemos a dificuldade e o esforço em tentar usar uma abordagem não diretiva. Ouvir a paciente foi o principal objetivo de todo o processo.

Percebemos na paciente sentimentos de ambivalência, devido à mudança da Instituição para a cidade, manifestados nas reflexões sobre os problemas que está enfrentando e tentando elaborá-los, visando a vontade de mudar.

Como refere RUDIO (1991), o terapeuta nãodiretivo procura "decifrar"os sentimentos e idéias que foram expressos nas palavras, no tom da voz, na mímica, nos gestos, no contexto da frase, nas hesitações, no estilo do cliente. Por sua vez, o terapeuta procura expressar com suas próprias palavras tudo que pode decodificar das manifestações do cliente, dando respostas compreensivas que podem assumir, tres formas diferentes: reiteração ou reflexo simples, reflexos dos sentimentos e elucidação.

No diálogo acima, as formas de respostas em E5 e E8, por exemplo, visavam reiteração. Segundo RUDIO (1991), a reiteração é apenas uma repetição do que o cliente disse. Utiliza-se, quando se quer destacar algo a fim de chamar a atenção do cliente sobre isso, ou quando se quer manifestar apenas compreensão ou ausência de julgamento.

Em E11 e E12, por exemplo, ficamos em dúvida se as intervenções foram do reflexo de sentimento, ou interpretativas. Segundo RUDIO (1991), o reflexo de sentimento serve para que o cliente tome consciência de elementos que compõem o campo do que ele pensa e sente e que, de certo modo, já foram manifestados pela sua expressão, embora não de modo explícito, dando-lhe oportunidade para ampliar e, mesmo, modificar seu campo de percepção.

Não houve oportunidade neste diálogo de eu utilizar a forma elucidativa de comunicação. A resposta elucidativa ocorre, segundo RUDIO (1991) quando o terapeuta faz uma inferência de algo que já estava no campo perceptivo do cliente, mas ainda não estava sob o seu foco perceptivo. Por isso, com muita frequência, o 
cliente tende a rejeitar a inferência e em não a reconhecer como algo que ele pensa ou sente.

Finalizando, entendemos que foi uma comunicação terapêutica enfermeiro-paciente pelas características já apontadas.

Vale ressaltar que devido à formação tradicional do enfermeiro, como sendo o dono do saber, a oportunidade de não diretividade requer maior esforço. Entretanto é um momento rico no processo de amadurecimento pessoal e profissional, trabalhando de uma maneira que respeite o outro com todas as suas complexidades. Nesta abordagem, procura-se dar ao indivíduo a oportunidade de conhecer-se, aceitar-se e inserir-se em seu próprio processo de vida, utilizando recursos pessoais para transformações construtivas de atitudes e comportamentos, como citam BRAGA \& RODRIGUES (1992).

\section{CONSIDERAÇÕES FINAIS}

Experienciar uma interação enfermeiro-paciente, com uma abordagem não diretiva, embasada em um referencial teórico centrando a atenção no paciente/ pessoa e não em seu problema, percebemos dificuldades e limites que o enfermeiro enfrenta no seu cotidiano.

Na prática, esta vivência nos coloca em contato com as idéias que são transmitidas durante a formação educacional do enfermeiro como sendo o dono do saber, portanto impondo poder e autoridade sobre o paciente.

A oportunidade de uma abordagem não diretiva na relação de ajuda requer maior esforço do enfermeiro para manter uma atitude de interesse aberto de uma pessoa pela outra, onde não haja julgamento e crítica.

Nesta interação, pudemos captar o esforço que o enfermeiro teve que empreender para em decifrar os sentimentos e idéias do paciente que foram expressos nas suas palavras, no tom de sua voz, nos seus gestos, nas hesitações e a tentativa de compreender o outro em sua própria maneira de expressar-se e de pensar, de acordo com seu mundo subjetivo.

A experiência vivenciada nos permitiu observar que a ansiedade do enfermeiro foi identificada principalmente no que se refere à aplicação da técnica. A ansiedade do paciente refletia as consequências de sua adaptação, fora do ambiente hospitalar após 25 anos de reoclusão.

A realização dessa atividade interativa contribuiu no processo de amadurecimento pessoal e profissional do enfermeiro, pois possibilitou a reflexão sobre suas atitudes não só como um elemento terapêutico, mas como um ser social. Assim,o olhar do enfermeiro não encontra um "corpo doente", mas uma pessoa singular, com sua história de vida e que tem dificuldades e potencialidades a serem superadas e desenvolvidas.

\section{NON-DIRECTIVE NURSE-PATIENT RELATIONSHIP IN THE PROCESS OF RE- SOCIALIZATION}

The present study aimed at analysing a nurse-patient interaction through a non-directive approach, centred in the care to patients in the stage of re-socialization. It was based on Rogers' studies and their application in nursing by Braga and Rodrigues. A new project of re-socialization of patients from a state hospital was followed. A patient participating in this program agreed to be interviewed with a nurse. The non-directive relationship was registered and analysed, focussing on the nurse's feelings, as well as her interventions considering verbal and non-verbal communication. The anxiety of the nurse was identified especially regarding technical application and the patient's anxiety reflected the consequences of her adaptation outside the hospital environment.

KEY WORDS: re-socialization, psychiatric nursing, interpersonal relationship

\section{RELACIONAMIENTO NO DIRECTIVO DEL ENFERMERO CON PACIENTE EN PROCESO DE RESOCIALIZACIÓN}

Este trabajo tuvo como objetivo experimentar y analizar una intervención enfermera-paciente con un abordaje no directivo, centrando la atención en el paciente en la fase de resocialización. Tuvo como hilo conductor principios extraídos de los trabajos de Rogers y de su aplicación en la enfermería hechos por Braga y Rodrigues. El nuevo proyecto de resocialización de pacientes de un macrohospital es supervisado y cuenta con una vivienda-ciudad donde los pacientes experimentan llevar sus vidas como ciudadanos comunes. Una paciente en fase de adaptación admitió participar de la entrevista con el enfermero. La dirección no directiva fue registrada y analizada, resaltándose los sentimientos del enfermero, así como sus intervenciones, considerando la comunicación verbal y no verbal. La ansiedad del enfermero fue identificada principalmente en lo que se refiere a la aplicación de la técnica y la ansiedad de la paciente reflejaba las consecuencias de su adaptación fuera del ambiente hospitalario. 


\section{REFERÊNCIAS BIBLIOGRÁFICAS}

01. BRAGA, V.A.B.; RODRIGUES, A.R.F. Análise crítica de um relacionamento enfermeiro paciente: tentativa de uma abordagem não-diretiva. In: $3^{\circ}$ SIBRACEn. Anais. Ribeirão Preto, 1992. p.190204.

02. MUCHIELLI, R. A entrevista não-diretiva. São Paulo: Martins Fontes, 1978. 186 p.
03. RODRIGUES, A.R.F. Relações interpessoais enfermeiro-paciente: análise teórica e prática com vista à humanização à assistência à saúde mental. Ribeirão Preto, 1993. 187 p.Tese (LivreDocência) - Escola de Enfermagem de Ribeirão Preto, Universidade de São Paulo.

04. RUDIO, F.V. Orientação não-diretiva na educação, no aconselhamento e na psicoterapia. Petrópolis: Vozes, 1991. 109 p. 